\title{
Das DH Förderprogramm startet in 2. Runde
}

Das miradent DH Förderprogramm 2016 für zukünftige Dentalhygieniker/innen fördert erneut die Weiterbildung von 10 Prophylaxefachkräften zur DH mit einem Gesamtbetrag von $25000 €$. Bereits 2015

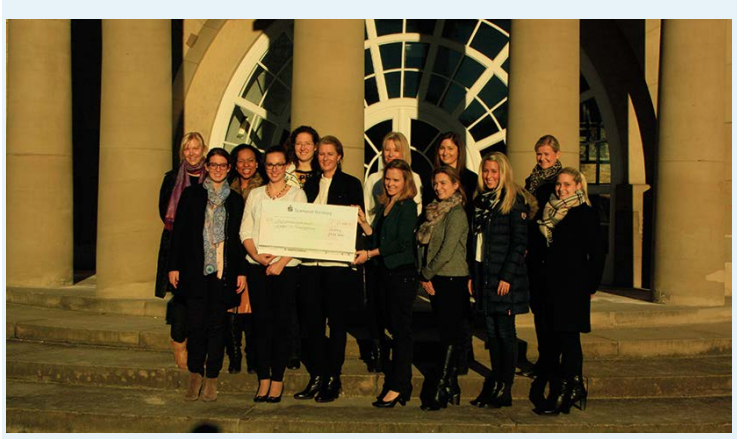

wurden 10 engagierte und motivierte Prophylaxefachkräfte ausgewählt und in Ihrer Ausbildung unterstützt und begleitet. Aufgrund der hohen Nachfrage und dem Willen auch weiterhin an der richtigen Stelle zu fördern wird Hager \& Werken 2016 erneut 10 Prophylaxefachkräften die Möglichkeit geben, ihr nächstes Karriereziel zu erreichen. Die Weiterbildungen sind für den nächsten Bewerbungs- und Kurszeitraum im kommenden Jahr an folgenden Standorten vorgesehen: dem ZfZ in Stuttgart, dem Phillip Pfaff Institut in
Berlin, dem NfI in Hamburg und der eazf in München und Nürnberg (weitere Institute nach Absprache).

Wer kann sich für die Förderung bewerben? Jede fortgebildete Fachkraft (ZMF, ZMP - m/w), mit dem Wunsch DH zu werden, hat die Möglichkeit, eine Bewerbung einzureichen. Förderlich sind gute Fachkenntnisse, Liebe am Beruf, eine hohe Eigenmotivation sowie gute Softskills für die Arbeit am und mit dem Patienten. Das Auswahlkomitee besteht aus Sylvia Fresmann (Präsidentin der DGDH), PD Dr. Dirk Ziebolz (Oberarzt für interdisziplinäre Zahnerhaltung und Versorgungsforschung an der Universität Leipzig) und Marcus van Dijk (Sales \& Marketing Director Europe bei der Hager \& Werken $\mathrm{GmbH}$ \& Co. KG).Bewerber/innen laden sich unter www.hagerwerken.de - News bitte das aktuelle Bewerbungsformular herunter. Einsendeschluss ist der 30. September 2016. Die Bewerbung ist unverbindlich und weder die Bewerber(innen) noch die finalen Stipendiaten gehen vor oder nach der Auswahl irgendeine bindende Verpflichtung ein.

Nach einer Pressemitteilung der Hager \& Werken GmbH \& Co. KG, Duisburg 